https://www.amerabra.org; https://fspu.uitm.edu.my/cebs; https://www.emasemasresources.com/

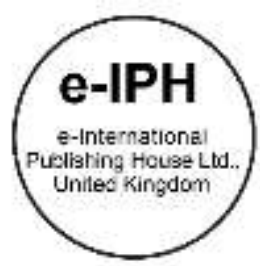

\title{
What Matters for Retirees to Experience a Great Quality of Life?
}

\author{
Nor Azilah Husin'1, Mazni Saad 2, Eka Mariyanti ${ }^{3}$, Norfadzilah Abdul Razak 4 \\ ${ }^{1}$ Faculty of Business and Accountancy, Universiti Selangor, 40000, Shah Alam, Selangor, Malaysia. \\ ${ }^{2}$ Tourism Department, Kulliyyah of Languages and Management, \\ International Islamic University Islam Malaysia, Edu Hub Pagoh, KM1 Jalan Panchor, Muar 84600 Johor, Malaysia. \\ 3 Faculty of Economics and Business, Universitas Dharma Andalas, Padang, West Sumatra-Indonesia \\ ${ }^{4}$ Faculty of Business and Management, Universiti Teknology MARA, 42300 Puncak Alam, Selangor, Malaysia.
}

nor_azilah@unisel.edu.my, maznisaad@iium.edu.my, ekamariyanti@yahoo.com,norfadzilah0438@uitm.edu.my

Tel of 1st Author: +6017-8787543

\begin{abstract}
This paper aims to identify the retirees' quality of life. A quantitative method and probability sampling technique were employed using a random selection of 210 retirees. The data is analysed using correlation and multiple regression analysis. The finding revealed that financial resources is the most influential element that influences the retirees' quality of life, followed by healthcare. Emotion does not affect their quality of life. The roles of government and private agencies such as banks, insurance, hospital, and caretakers of the retirees aware of their needs, and provide facilities to ensure a better quality of life.
\end{abstract}

Keywords: financial resources; emotion; healthcare; retiree quality of life

eISSN: 2398-42870 2021. The Authors. Published for AMER ABRA cE-Bs by e-International Publishing House, Ltd., UK. This is an open access article under the CC BYNCND license (http://creativecommons. org/licenses/by-nc-nd/4.0/). Peer-review under responsibility of AMER (Association of Malaysian Environment-Behaviour Researchers), ABRA (Association of Behavioural Researchers on Asians/Africans/Arabians) and cE-Bs (Centre for Environment-Behaviour Studies), Faculty of Architecture, Planning \& Surveying, Universiti Teknologi MARA, Malaysia. DOI: https://doi.org/10.21834/ebpj.v6i17.2787

\subsection{Introduction}

Retirement is the withdrawal from one's position or one's active working life. When individual retirees from their paid employment, they no longer enjoy the salary and perks they used to have, despite the continuing costs associated with life (Husin, 2017). An individual may likewise semi-resign by diminishing work hours. An expanding number of people decide to put off this place of absolute retirement by choosing to exist in the arising condition of pre-retirement. Some people have retired from a position with a pre-nominal title (Orlovic, Smith, \& Mossialos, 2019).

Furthermore, retirement involves exiting the full-time labor force. Retirement is an inevitable life change for many, but what it entails can differ markedly between people. The Minimum Retirement Age Act 2012 states that the base retirement age of a worker will arrive accomplishing the age of 60 (Sun daily, 2019).

However, this need not mean stopping all forms of work, as some people still choose to engage in unpaid employment or continue working in a part-time capacity (Haslam et al., 2019). Each individual's retirement life is different. People perceive retirement from many different perspectives.

Malaysians already face multiple challenges when planning for their retirement years, such as a lack of financial planning, their health, and emotion. These issues will be compounded in the coming decade, thanks to longer life expectancy and lower economic

eISSN: 2398-4287@ 2021. The Authors. Published for AMER ABRA cE-Bs by e-International Publishing House, Ltd., UK. This is an open access article under the CC BYNCND license (http://creativecommons.org/licenses/by-nc-nd/4.0/). Peer-review under responsibility of AMER (Association of Malaysian Environment-Behaviour Researchers), ABRA (Association of Behavioural Researchers on Asians/Africans/Arabians) and cE-Bs (Centre for Environment-Behaviour Studies), Faculty of Architecture, Planning \& Surveying, Universiti Teknologi MARA, Malaysia.

DOI: https://doi.org/10.21834/ebpj.v6i17.2787 
growth. Malaysia's populace development is about $1 \%$ per year, while that of the old is about $5 \%$, expected to grow faster (Zhe, 2019). Mostly in Malaysia, many workers do not retire because they are worried about their income. Additionally, the economic needs nowadays decrease, and some of them have low salaries among Employee Provident Fund (EPF) members lead to lower savings, affecting their retirement future. Hence, the objective of this study is, therefore, to identify the relationship between financial resources, emotion, healthcare, and the retiree's quality of life.

\subsection{Literature Review}

\subsection{Retirees Quality of Life}

Retirement is an important and complex period for those experiencing it (Yeung \& Zhou, 2017). To promote the well-being of this segment of the population and measures are needed. The living condition has always been related to appropriate welfare concerning culture, individual expectations, and values. A theoretical contribution to focusing on human virtues and qualities as a counterpoint to illness and suffering is the most critical positive psychology serving (Amorim, Silvia \& Lucia Helena Freitas, 2019). Welfare is composed of emotions and overall judgment or essential domains of life. Research has been done in the University of South-Eastern Norway that finds most new retirees have the same quality of life as they are still working. But it is not applied to everyone (Jakobsen, 2019).

The perception of well-being influenced the reason that an individual makes to retire. For example, unplanned retirement can have negative consequences (Yeung \& Zhou, 2017). This assumption proves that retirement decisions may link to individual issues of financial, family and health. Satisfaction with retirement has been come up with a subjective sense of welfare that shows how individuals understand their quality of life at the moment. Retirement satisfaction does not represent the process but instead an indicator of interest and satisfaction with retiring life (Dahlan, Ahkehsan, et al., 2016).

Schlossberg (2017) reiterated that many retirees feel pressured by their own family based on their family needs. For example, the retirees had to babysit their grandchildren. Unsatisfying retirement mostly happens when they do not invest in their friendship before they retire and do not talk openly with family about their goals. Some people struggle to adjust to new life during retirement, who reported more boredom, uselessness, restlessness, and anxiety (Burton, 2019). People may go through hell when they retire, and they refuse to tell anybody about it because they are embarrassed. This is the reason why people need to invest as much as they can in their social life before retirement to sort out what satisfies them (Amorim et al., 2019).

\subsection{Financial Resources}

A financial arrangement might be made autonomously or with the assistance of a guaranteed financial planner-retirees. Regardless, it starts with a careful assessment of the person's present economic state and future assumptions. The retiree's future finances will determine the retirement goal, for instance, in the event of a promotion. For example, if the retiree's dependent and debt has gone down, they do not need life insurance coverage as much. The most cautious plans and groundwork for retirement can self-destruct because of quite a few post-retirement chances: a startling demise, a lung disease, a securities exchange crash, or an annuity plan that fails. Planning for retirement starts with thinking about the retirement goals and how long retirees have to meet them. Looking for retirement accounts that can help retirees raise the money to fund their future is also essential. As the retirees save that money, they have to invest it in enabling it to grow. Retirees also have to make sure that they have enough money for at least 30 years of retirement. Retirement also leads to interest rate risk. Lower interest rates reduce retirement income by lower growth sales for saving accounts and assets (Kagan, 2020). Medical care is the essential wellspring of inclusion for medical care administrations for some retired folks. Private health care coverage is additionally accessible. However, it very well may be expensive and not affordable.

Subsequently, people may have to save more to collect reasonable retirement reserves. Annuities yield less pay when long-haul loan fees at the hour of procurement are low. Lower interest rates will also cause purchasing power to erode mode rapidly. Lower loan costs can lessen retirement pay and can be especially hazardous when quickly. Retirees depend on drawdown from investment funds to back their retirement. Then again, an issue additionally exists if financing costs ascend as bonds drop. Financial planning simply refers to saving up money for the future. Certain people start saving for retirement without knowing how much they will need to maintain their living standards after retirement (Hawkins, 2020). To further explore this relationship regarding specifically financial resources and retirees' quality of life, this study proposes the following hypothesis:

$\mathrm{H} 1$ : There is a significant relationship between financial resources and retirees' quality of life.

\subsection{Emotion}

There are not many people who consider the psychological adjustments during retirement, including coping with the loss of retirees' careers, spending more time with their partners, and finding new ways to stay active (Burton, 2019). Some still act like they are still working, and yet they are not. Some retirees enjoy their retirement by spending more time with hobbies or family and friends. But there are some of them that experience anxiety, depression, and debilitating feelings of loss. There will be no other stage of life that triggers an intense sense of excitement and liberation, but instead, they feel fear and anxiety.

Retirement is a significant transition that unfolds over many years. The retirees will get to know a new life, which is different from their life. Many retirees do not fully prepare and comprehend how their life would dramatically change.

Those who have stopped working from a very long-term service have quite challenging emotions. A longitudinal study of Srinivas et al. (2020) among the 12,350 participants has indicated that adolescent negative emotion is significantly associated with cardiovascular disease (CVD), although socio-demographic characteristics, socioeconomic status, and medical conditions are controlled in the logistic 
regression analysis. In this study, emotions were measured by perception of life, self-reported depression, perceived loneliness, and fearfulness. The researchers suggested that the preventive care approach may improve the quality of care and health and lower costs by adopting appropriate quality improvement strategies that may aid preventive care.

Harrington et al. (2021) recently investigated if memorable experiences translated into enhanced life satisfaction during the Oktoberfest event, one of the hospitality businesses serving food and drink. Their findings showed that meaningfulness and memorability had a significant positive effect on their life satisfaction, and it also partially mediated the relationship with experience uniqueness. In this study, life satisfaction was measured by transformative experiences derived from positive emotions, engagement, relationships, meaningfulness, and accomplishments. Based on the literature review, this study would like to postulate that:

\section{$\mathrm{H} 2$ : There is a significant relationship between emotion and retirees' quality of life.}

\subsection{Healthcare}

Retirees are always associated with being sick and depressed. Depression is more common in retirees, with compulsory pensions, ill pensions, and anticipated retirement showing higher disease rates. Pabón-Carrasco et al. (2020) discovered that nearly a third of retirees suffer from depression; it is necessary to take precautions and early detection to approach public health problems. Unexpected medical bills in terms of health care are a significant concern for many retirees. Healthcare is not free. Just like any insurance, they pay premiums, deductibles, coinsurance for standard medical services. Healthcare also can be one of the most significant expenses. Lake (2020) stated that in health care in retirement, 65 years-old couples retiring in 2019 can expect to spend $\$ 285,000$ in healthcare and medical expenses throughout retirement. Prescription drugs are a significant issue, especially for the chronically ill. Older people usually have more substantial health care needs and may require frequent treatment for several different health-related problems.

Meanwhile, Taboada-Vazquez, Gonzalez-Rodriguez, Gandoy-Crego, and Clemente (2021) stated that people who work actively use more behavioral coping strategies and cognitive avoidance of problematic situations, while retirees do not avoid thinking about such cases. In the end, retirees blame themselves for their problems, they do not prevent this thought, and they also strengthen themselves by thinking about their past and are disturbed by the present.

Frimmel \& Pruckner (2020) postulated that increasing the retirement age can have unwanted side effects related to retirees' health or healthcare costs. They analyzed the impact of early retirement on individual hospitalization and utilization of outpatient health services in Austria; Austria has a Bismarck type health care system that provides the entire population with universal access to medical services. They found a significant negative effect of pensions on service utilization. Retirement reduces subsequent doctor visits and expenditures on outpatient and inpatient medical care. To further explore this relationship regarding specifically healthcare and quality of life, this study proposes the following hypothesis:

H3: There is a significant relationship between healthcare and retirees' quality of life.

To sum up, based on the presented literature, the quality of life framework is illustrated in fig. 1:

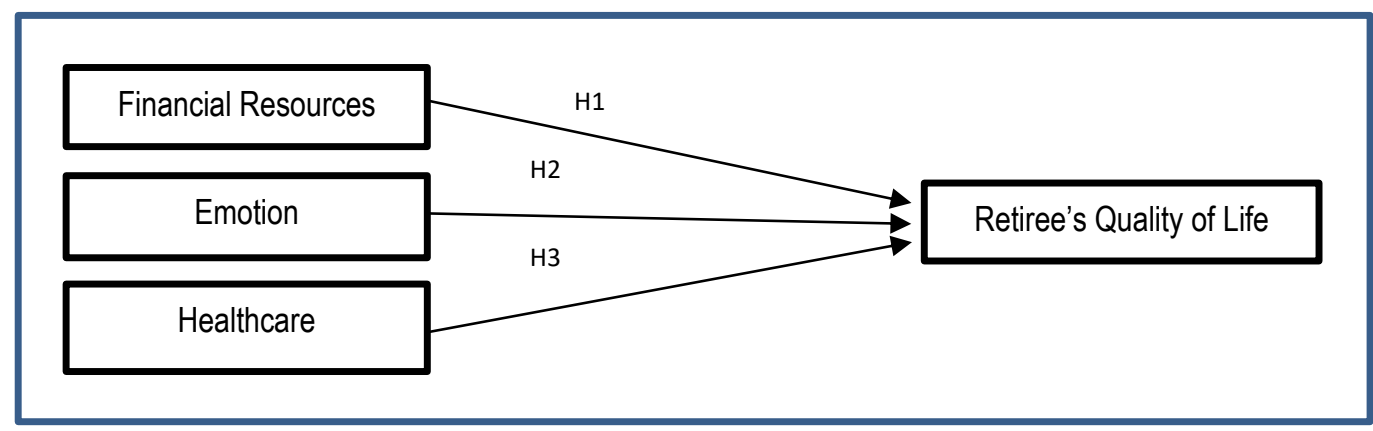

Figure 1. Research Framework

To better understand how retirees perceive the quality of life, this study is guided by the quality of life theory. Maslow based his theory for development towards happiness and being on the concept of human needs. He described his methodology as an existentialistic brain science of self-realization given self-improvement (Ventegodt, Merrick, \& Andersen, 2003). Thus, this study will only focus on financial resources, emotions, and healthcare as based on the literature review, these are the factors that affect one's quality of life.

\subsection{Methodology}

The target population is retirees in Selangor. The number of retirees in Selangor in 2020 is 66538 (Employment Insurance System,2020). This study used probability sampling and simple random sampling techniques to provide the researchers with a generalized sample-a total of 210 questionnaires to pensioners through social networking systems, including WhatsApp Messenger and Telegram. The rate of the respondent is $100 \%$. Data collection took place from 13 October 2019 to 30 December 2019 . The test result only valid is the number of actual respondents aligned with the target population for the study. 
This study adopted a self-administered survey approach and developed the questionnaire through a review of the literature. The questionnaire survey consisted of five sections that were adapted from previous studies. The respondents of this study were requested to indicate their level of perceptions on a 7-point Likert Scale, ranging from Strongly Disagree (1) to Strongly Agree (7). Finstad (2010) contended that 7-point scale Likert items are more suitable for electronically transmitted and otherwise unsupervised usability questionnaires since they offer a more precise indicator of a participant's accurate evaluation. The set of questionnaires is formulated based on the chosen variables from the previous studies: quality of life (Haslam et al., 2018), financial resources (Mary, Ming \& Lee, 2016; Topa et al., 2018), emotion (Schmitt, Coyle, Rauschenberger \& White, 1979), and healthcare (Daugherty, 2019).

A reliability test is conducted to see whether the questionnaires are reliable. The questions from questionnaires are taken and analysed with the SPSS software system to determine the reliability. The result of Cronbach Alpha for every variable is presented in the below table. The result indicates that items with high internal consistency, like Cronbach Alpha Values, were greater than 0.5 (Henseler, Hubona, \& Ray, 2016)

Table 1. Result of Cronbach's Alpha for the Variable Items

\begin{tabular}{lcc}
\hline Variables & Cronbach Alpha & Number of Items \\
\hline Financial Resources & 0.903 & 5 \\
Emotion & 0.809 & 3 \\
Healthcare & 0.824 & 5 \\
Retiree's Quality of Life & 0.843 & 5 \\
\hline
\end{tabular}

\subsection{Findings}

\subsection{Sample Profile}

Overall, the total number of respondents obtained was 210 . In terms of gender, $52.9 \%$ were male while the rest, $47.1 \%$, were female. Out of 210 respondents, $60.0 \%$ were in the age range from $50-55$ years old. $72.4 \%$ of the respondents are recorded as Malay, and most of them are married, with a percentage of $81.0 \% .59 .9 \%$ of the retirees who retired from the private sector, majority of them have been retired for $1-5$ years $(72.4 \%)$. Lastly, most of the respondents are good in health, with a percentage of $73.3 \%$. The illustration of respondents' demographic factors is illustrated as below:

Table 2. Retiree's Demographic Profile

\begin{tabular}{|c|c|c|}
\hline Particulars & $\mathrm{N}=210$ & $(\%)$ \\
\hline \multicolumn{3}{|l|}{ Gender } \\
\hline Male & 111 & 52.9 \\
\hline Female & 99 & 47.1 \\
\hline \multicolumn{3}{|l|}{ Age } \\
\hline $50-55$ years old & 126 & 60.0 \\
\hline 56 years old and above & 84 & 40.0 \\
\hline \multicolumn{3}{|l|}{ Race } \\
\hline Malay & 152 & 72.4 \\
\hline Chinese & 27 & 12.9 \\
\hline India & 31 & 14.7 \\
\hline \multicolumn{3}{|l|}{ Marital status } \\
\hline Single & 23 & 11.0 \\
\hline Married & 170 & 81.0 \\
\hline Divorce & 17 & 8.0 \\
\hline \multicolumn{3}{|l|}{ Religion } \\
\hline Islam & 152 & 72.4 \\
\hline Buddha & 15 & 7.1 \\
\hline Hindu & 26 & 12.4 \\
\hline Christian & 17 & 8.1 \\
\hline \multicolumn{3}{|l|}{ Retired from? } \\
\hline Private & 125 & 59.5 \\
\hline Government & 85 & 40.5 \\
\hline \multicolumn{3}{|l|}{ How long have you been retired? } \\
\hline $1-5$ years & 152 & 72.4 \\
\hline 6 years above & 58 & 27.6 \\
\hline \multicolumn{3}{|l|}{ Health condition } \\
\hline Healthy & 150 & 73.3 \\
\hline Not healthy & 54 & 23.8 \\
\hline Bad condition & 6 & 2.9 \\
\hline
\end{tabular}




\subsection{Pearson Correlations}

Refer Table 3, the correlation coefficient between retirees' quality of life and financial resources is a moderate relationship at 0.644 with a significant level of 0.000 . Next, the finding found that quality of life and emotions have a low relationship correlation of 0.362 with a significant level of 0.000 . The last one, quality of life and health care, have a moderate relationship correlation of 0.453 with a significant level of 0.000 . Overall, the result revealed a significant relationship between financial resources, emotional and health care, and quality of life among retirees. The significant level of each variable was less than 0.05 .

\begin{tabular}{lcccc} 
& \multicolumn{3}{c}{ Table 3. Correlation Analysis } & \\
\hline & Quality of life & Financial Resources & Emotion & $.453^{* *}$ \\
\hline Quality of life & & $.644^{* *}$ & $.362^{* *}$ & $.541^{* *}$ \\
Financial Resources & $.644^{* *}$ & & $.463^{* *}$ & $.406^{* *}$ \\
Emotion & $.362^{* *}$ & $.463^{* *}$ & & $.406^{* *}$ \\
Healthcare & $.453^{* *}$ & $.541^{* *}$ &
\end{tabular}

Correlation is significant at 0.01 level (2-tailed)

* Correlation is significant at 0.05 level (2-tailed)

\subsection{Linear Regression Analysis}

After conducting Pearson Coefficient analysis, linear regression analysis was applied to determine the most influential factors influencing the quality of life among retirees. Refer to Table 4 , financial resources $(\beta=0.546, p<0.05)$ and health care $(\beta=0.136, p<0.05)$ were factors that influence the quality of life. Thus, hypothesis 1 and hypothesis 3 were supported as the significant values were less than 0.05 . However, the finding of emotions contradicts as the p-values were greater than 0.05 and indicated the Hypothesis 2 was not supported. The adjusted R2 is 0.433 , which means 43.3 percent variance of these independent variables contributes to the retirees' quality of life. The test showed the value is $p=0.000$; therefore, the result is a significant relationship between retiree quality of life and financial resources.

Table 4. Regression Analysis Results

\begin{tabular}{|c|c|c|c|}
\hline Hypothesis & Standardized coefficients & Sig. & Conclusion \\
\hline \multicolumn{4}{|l|}{$\mathrm{H} 1$ : There is a significant relationship between Retirees } \\
\hline Quality of Life and Financial Resources & .546 & .000 & Supported \\
\hline \multicolumn{4}{|l|}{$\mathrm{H} 2$ : There is significant relationship between Retirees } \\
\hline Quality of Life and Emotion & .054 & .371 & Not Supported \\
\hline \multicolumn{4}{|l|}{ H3: There is a significant relationship between Retirees } \\
\hline Quality of Life and Health Care & .135 & 035 & Supported \\
\hline
\end{tabular}

\subsection{Discussions}

Retirement preparations such as financial status impact social and economic capital, and job engagement affects motivational and emotional resources in retirement (Zacher \& Schmitt, 2016). Similar to a study stated that improved healthcare solicitation and the social world of older adults are intricately connected, according to Dovie's (2018) research. Meanwhile, emotions do not show a significant relationship with their dependent variable. It contradicts with few studies which stated, (i.e., Harrington et al. (2021), Srinivas et al. (2020), showing that emotion has affected the retirees' quality of life. These results could be justified as the majority of the respondents (72.4\%) have just about one to five years, recently retired, and are mostly $(73.3 \%)$ in a healthy condition. They are still happy and fit. Several studies have shown that retirement planning and preparation positively impact retirement goals, positive attitudes toward retirement, and retirement anxiety. Related programmes or activities assist participants in developing reasonable retirement expectations (Taylor \& Schaffer, 2018). The government or private agencies such as banks, insurance, hospitals, and senior citizen caretakers must prepare these retirees with financial and healthcare management so that they can experience an excellent quality of life. However, two possible limitations of this study are that it only evaluated retirees from Selangor state, and there are only two age categories: 50 to 55 years old and 56 years old and above. The retirees from other states and much older respondents could yield different results.

\subsection{Implications}

The significant implication of the study is towards general knowledge of the people. Financial management is crucial. The retiree should have planned and saved much earlier. Future cash flows are assessed to determine the achievement of the retirement income goal. Retirement planning refers to financial strategies of saving, investment, and ultimately distributing money meant to sustain oneself during retirement. The following implication is towards the practitioner, who are responsible for providing the information related to retirement, the process of determining retirement income goals, and the actions and decisions necessary to achieve those goals. The related stakeholders such as banks, insurance, hospitals, and caretakers of the elderly also need to identify sources of income, estimating 
expenses, implementing a savings program, and managing assets and risk. Healthcare is also vital; retirees will have to allocate some allocations for insurance and healthcare and act actively to be healthy. Leading a healthy lifestyle after retirement is crucial. Most standard insurance does not provide adequate coverage. Essential knowledge about retirement planning is to prepare for all aspects of life after work.

\subsection{Conclusion \& Recommendations}

The study proved their financial resources and healthcare significantly influence the retiree's quality of life. In contrast, emotion does not significantly affect their quality of life. Perhaps, once they have wealth and health, it is good enough to have a great quality of life. As they age, they could smartly control their emotion. Aging makes them wiser. For future studies, researchers could consider using larger samples from various ethnic groups from different countries, such as countries in Asia, to better represent a larger population to avoid under-representation. It is suggested that a longitudinal study design test the causal relationship between the variables constructs in this model.

\section{Acknowledgements}

We would like to thank all participants for their honest response. .

\section{Paper Contribution to Related Field of Study}

This study is related to the study of quality of life and elderly environment.

\section{References}

Amorim, Silvia M., and Lucia Helena Freitas, P. França. "Retirement Well-Being: A Systematic Review of the Literature." Temas Em Psicologia, vol. 27, no. 1, 2019, pp. 155-172., doi:10.9788/tp2019.1-12.

Burton, 2019, You're probably not ready to retire — psychologically marketwatch.com/story/why-youre-probably-not-psychologically-ready-to-retire-2019-05-21

Dahlan, Akehsan, et al. "Role of the Physical Environment and Quality of Life amongst Older People in Institutions: A Mixed Methodology Approach." Procedia - Social and Behavioral Sciences, vol. 234, 2016, pp. 106-113., doi:10.1016/j.sbspro.2016.10.225

Daugherty, Greg. "The Pros and (Mostly) Cons of Early Retirement." Investopedia, Investopedia, 14 Apr. 2020, investopedia.com/articles/personal- finance/073114/prosand-mostly-consearly- retirement.asp.

Dovie, D. A. (2018). Leveraging healthcare opportunities for improved access among Ghanaian retirees: The case of active aging. Social Sciences, 7(6), 92.

Employment Insurance System (EIS), 2020 Accessed via https://eiscentre.perkeso.gov.my/wp-content/uploads/2020/03/Employment-Outlook-Volume-1-2020 Establishments.pdf

Finstad, K. (2010, May). Response Interpolation and Scale Sensitivity: Evidence Against 5-Point Scales. Journal of Usability Studies , 5(3), $104-110$.

Frimmel, W., \& Pruckner, G. J. (2020). Retirement and healthcare utilization. Journal of Public Economics, 184.

Harrington, R.J., Ottenbacher, M.C., Schmidt, L, Murray, J.C., \& Freyberg, B.v. (2021). Experience perceptions, memorability and life satisfaction: a test and theory extension in the context of Oktoberfest. International Journal of Contemporary Hospitality Management, 33(2),735-754.

Haslam, C., Steffens, N. K., Branscombe, N. R., Haslam, S. A., Cruwys, T., Lam, B. C., ... \& Yang, J. (2019). The importance of social groups for retirement adjustment: evidence, application, and policy implications of the social identity model of identity change. Social issues and policy review, 13(1), 93-124.

Haslam, C., Lam, B. C., Branscombe, N. R., Steffens, N. K., Haslam, S. A., Cruwys, T., ... \& Ball, T. C. (2018). Adjusting to life in retirement: the protective role of new group memberships and identification as a retiree. European Journal of Work and Organizational Psychology, 27(6), 822-839.

Henseler, J., Hubona, G. and Ray, P.A. (2016), "Using PLS path modeling in new technology research: updated guidelines", Industrial Management \& Data Systems, Vol. 116 No. 1, pp. 2-20. https://doi.org/10.1108/IMDS-09-2015-0382

Husin, N. A. B. (2017), Retirement Planning: Are Selangorians Ready?. In Annual Conference on Economics, Business, Accounting and Social Sciences (ACEBASS) 2017.

Jakobsen (2019), What makes a good life in retirement? A Norwegian researcher has investigated what makes recent retirees happy with their lives. Siw Ellen Jakobsen sciencenorway.no/pension-retirement/what-makes-a-good-life-in retirement/1643302

Kagan, Julia (2020). "Retirement Planning." Investopedia, Investopedia, 5 Feb. 2020, investopedia.com/terms/r/retirement-planning.asp.

Kuek Ser Kwang Zhe (2019), The Edge Malaysia July 18, 2019. Retrieved from theedgemarkets.com/article/longterm-challenges-retirement-planning 
Lake, Rebecca(2020). "How to Plan for Medical Expenses in Retirement." Investopedia, Investopedia, 5 Feb. 2020, investopedia.com/retirement/how-plan-medicalexpenses-retirement/

Mary, P., Ming, L. M., \& Lee, C. L. (2016). The resources and life satisfaction of retired women in Malaysia. Asia Pacific Journal of Advanced Business and Social Studies, 2(1), 212-21.

Orlovic, M., Smith, K., \& Mossialos, E. (2019). Racial and ethnic differences in end-of-life care in the United States: Evidence from the Health and Retirement Study (HRS). SSM-population health, 7, 100331.

Pabón-Carrasco, M., Ramirez-Baena, L., López Sánchez, R., Rodríguez-Gallego, I., Suleiman-Martos, N., \& Gómez-Urquiza, J. L. (2020). Prevalence of Depression in Retirees: A Meta-Analysis. Healthcare, 8(3), 321. https://doi.org/10.3390/healthcare8030321

Schmitt, N., Coyle, B. W., Rauschenberger, J., \& White, J. K. (1979). Comparison of early retirees and non-retirees. Personnel Psychology, 32(2), 327-340.

Srinivas, S., Anad, K., \& Chockalingam, A. (2020). Longitudinal association between adolescent negative emotions and adulthood cardiovascular disease risk an opportunity for health care quality improvement. Benchmarking: An International Journal, 27(8), 2323-2339.

Taboada-Vazquez, A., Gonzalez-Rodriguez, R., Gandoy-Crego, M., \& Clemente, M. (2021). Psychological profile and consumption of healthcare resources in actively employed people, pre-retirees, and retirees. Sustainability (Switzerland), 13(8), 1-11. https://doi.org/10.3390/su13084415

Taylor, M. A., \& Schaffer, M. (2018). Planning and adaptation to retirement: The post-retirement environment, change management resources, and need- oriented factors as moderators.

Topa, Gabriela, et al. "Financial Planning for Retirement: A Psychosocial Perspective." Frontiers in Psychology, vol. 8, 2018, pp. 1-8., doi:10.3389/fpsyg.2017.02338.

Ventegodt, S., Merrick, J., \& Andersen, N. J. (2003). Quality of life theory III. Maslow revisited. TheScientificWorldJOURNAL, 3, $1050-1057$.

Yeung, D. Y., \& Zhou, X. (2017). Planning for retirement: Longitudinal effect on retirement resources and post retirement well-being. Frontiers in Psychology, 8, 1-14. doi: 10.3389/ fpsyg.2017.01300.

Zacher, H., \& Schmitt, A. (2016). Work characteristics and occupational well-being: The role of age. Frontiers in Psychology, 7, 1411. doi: 10.3389/fpsyg.2016.01411 